MEDICAL EDUCATION

\title{
Establishing the Diploma in Tropical Medicine and Hygiene (DTM\&H) course in the Sultanate of Oman
}

\author{
E M Scrimgeour
}

Postgrad Med J 2004;80:221-223. doi: 10.1136/pgmj.2003.015594

Until 1997, there was no formal teaching in tropical medicine in Arabian Peninsular countries, although many tropical diseases (for example, malaria, schistosomiasis, leishmaniasis, filariasis), are endemic in the region. A six month, part time Diploma in Tropical Medicine and Hygiene (DTM\&H) course was established in the Sultan Qaboos University, Muscat, Sultanate of Oman, in 1997, for small groups of Omani doctors wishing to sit the annual DTM\&H examination in London. To date, 21 doctors have been successful, and the Royal College of Physicians of London has accredited the Tropical Medicine School in Oman as an appropriate training centre for the examination. Since over 20 doctors apply each year for the six available places in the course, a full time DTM\&H course for larger groups of doctors, from Oman and regional countries, is under consideration.

Correspondence to: Dr Euan M Scrimgeour, Department of Medicine, Sultan Qaboos University, PO Box 35, Al-Khod (Muscat), 123, Sultanate of Oman; scrim@squ.edu.om

Submitted 4 October 2003 Accepted 30 October 2003
U ntil 1997, there was no formal tropical medicine teaching available in Arabian Peninsular countries, despite the fact that many exotic conditions (for example, malaria, schistosomiasis, leishmaniasis, filariasis), are endemic in this part of the Middle East. ${ }^{1-3}$ This Diploma in Tropical Medicine and Hygiene (DTM\&H) course at the Sultan Qaboos University, in Muscat, Oman.

\section{TROPICAL MEDICINE TEACHING IN THE UK}

In western countries, the study of tropical medicine is usually undertaken as an optional, additional subject, on completion of a traditional medical course. In the UK, tropical medicine was first taught over 100 years ago in Edinburgh University, Scotland, with the award in 1899 of a Certificate in Tropical Medicine. The Liverpool and the London Schools of Tropical Medicine were founded in the same year, and in the latter, a three month course in tropical medicine began on 2 October 1899. Satisfactory students were granted a "special certificate", while others who had attended the course (and not "merely sampled the delights of the capital") received an attendance certificate. In the 1890s, there was a pressing need to teach tropical medicine in the UK: British based doctors were encountering unfamiliar infections and exotic diseases, article describes the establishment in 1997 of a particularly parasitic infections, in returning servicemen, merchants, colonialists, and others who had visited tropical countries. ${ }^{4}$

The first DTM\&H was actually awarded by Cambridge University on 3 November 1903, to students including those from what would later become the London School of Hygiene and Tropical Medicine (LSHTM). The London course, in addition to preparing candidates for the Cambridge examination, "equipped men for the Diploma in the Diseases and Hygiene of the Tropics of the Conjoint Board (Royal College of Physicians of London and the Royal College of Surgeons of England)". The Liverpool School began a course for the Diploma in Tropical Medicine in 1904, and in Edinburgh, the Certificate in Tropical Medicine was replaced by the DTM\&H in 1905. In 1925, London University introduced the DTM\&H qualification, and the LSHTM ceased to issue certificates, but Liverpool retained its own diploma course, the Diploma in Tropical Medicine becoming the DTM\&H in 1946. The Liverpool course continues today.

Currently, the DTM\&H is awarded by the Royal College of Physicians of London to successful candidates who have completed the LSHTM course, and other candidates who have studied at a recognised training centre (see below). Regrettably, the oldest tropical medicine school in the UK, Edinburgh University, discontinued its DTM\&H course in 1971, following the retirement of the eminent Dr Frederick J Wright, who had ably run the course since 1958. The course ended at a time when tropical medical training was as important as ever.

In countries of the British Commonwealth, as medical schools opened up, their curricula followed the traditional British teaching system, with little emphasis on parasitic and other exotic diseases. In Calcutta, this discrepancy was rectified in 1920 when a Tropical Medicine School was founded, the first of its kind in a tropical country. In Australia, tropical medicine teaching only began in 1930, at the School of Public Health and Tropical Medicine in Sydney (the School superseded the research orientated Australian Institute of Tropical Medicine which was founded in 1910).

\section{NEED FOR TROPICAL MEDICINE TEACHING IN THE MIDDLE EAST}

A tropical medicine specialist working in Jeddah, Saudi Arabia in the early 1990s would have

Abbreviations: DTM\&H, Diploma in Tropical Medicine and Hygiene; LSHTM, London School of Hygiene and Tropical Medicine 
realised that there was an urgent need for tropical medicine teaching. Many tropical conditions were known to occur in Saudi Arabia, ${ }^{1-3}$ but clinical and epidemiological knowledge of these conditions was often sparse, and there was no adequate central reference source. (This was subsequently rectified..$^{5}$ ) Before going to Jeddah, the author had contributed to the part time DTM\&H course in Glasgow which prepared junior doctors for the formal London examination. In Jeddah, he offered to initiate a similar course with the strong support of Professor Keith P W J McAdam of the LSHTM, but the proposal was rejected by the hospital Postgraduate Education Committee in Jeddah on the grounds that "Tropical medicine was irrelevant to the training of young Saudi doctors".

On transfer to Muscat, Oman in 1995, it was clear to the author that there was also a pressing need for training in tropical medicine. The existing medical course followed the traditional western pattern with little emphasis on tropical diseases. Although the volume of parasitic and exotic conditions was relatively small in Oman, it was well represented. ${ }^{67}$ In addition, Oman has very close ties with East Africa, especially Mombassa, and Zanzibar and Pemba Island, which it administered until 1964. Following independence in Tanzania and Kenya, many hundreds of thousands of Swahili speaking, ethnic Arabs migrated to Oman, importing various tropical conditions.

\section{INTRODUCTION OF A DTM\&H COURSE IN OMAN}

Fortunately, the College of Medicine of the Sultan Qaboos University, was receptive to the idea of a DTM\&H course, and this was approved by the Oman Medical Specialty Board (representing the Ministry of Health and the University) in 1997. The Royal College of Physicians of London agreed to reserve places for Omanis in the April 1998, DTM\&H examination in London, and in August 1997, we enrolled seven young Omani doctors. This was to be a six month, part time course, conducted, jointly by the Departments of Medicine, and Family and Community Medicine (there was no Department of Public Health Medicine), with support from the Departments of Microbiology and Child Health. Teaching was in English, with weekly lectures, and monthly laboratory sessions were organised, utilising our extensive collection of teaching slides, and representative collection of parasite, arthropod, and mollusc specimens. Clinical cases were presented as they occurred, and trips were arranged to the regional leprosarium. Textbooks and print-outs of lectures were provided, and self assessment questionnaires were distributed after each lecture. Although the course was free, candidates were required to pay the cost of sitting the examination in London, a total of about $£ 800$.
The course proceeded with numerous expected and unforeseen difficulties. Two candidates abandoned the course after a few weeks, claiming that they did not have enough time to study parasitology, and were replaced by others. A course assessment (mock) examination was held in February 1998 before the deadline for registration for the London examination and four candidates prepared to go to London (three others lacking confidence, opted to withdraw). The three day examination was in five parts: multiple choice questions, short answer preventative medicine, projected materials, practical, and clinical/viva voce examinations, and it was essential to pass all five sections. When two of the candidates succeeded in passing, the future of the course seemed assured.

\section{FURTHER DEVELOPMENT OF THE COURSE}

The course has continued yearly since then, with six candidates in each course. We received early support from the Oxford Centre for Tropical Medicine, and subsequently, much encouragement and practical advice from the LSHTM. Our course and teaching have steadily improved, and we have enrolled more honorary tutors, including lecturers in pathology, haematology and entomology, and the World Health Organisation representative in Oman who lectures on the role of World Health Organisation and the Tropical Diseases Research Programme. Currently, we have had 21 passes and five failures (table 1). We have learned much from our returning candidates about the content of the London examination. No candidate has failed since the debacle of 2000 when three of six candidates failed (two of whom had passed four sections including the viva). It has been disappointing that for a variety of reasons five candidates have failed the rigorous, two day mock examination in the last three courses. Some of these candidates were studying for other examinations and were unable to devote enough time to the course. In 2002, the Royal College of Physicians of London accredited the "Tropical Medicine School" in Oman as an appropriate training centre for the examination, the other approved centres being London, Liverpool, Glasgow, Birmingham, Sheffield, and Bristol.

In retrospect, it was of course a gamble to initiate a DTM\&H course with relatively few local consultants with tropical expertise (which included three with the DTM\&H), and limited laboratory facilities. Despite these limitations, most of our candidates have worked with diligence and enthusiasm, and as a result, tropical medicine training has now become established in Oman. It is sought after by young doctors undertaking higher training in various disciplines, relatively few of whom could spare the time and expense to attend the London or Liverpool courses. Some 20 or more

\begin{tabular}{|c|c|c|c|c|}
\hline \multirow[b]{2}{*}{ Year } & \multirow[b]{2}{*}{ Enrolled students } & \multicolumn{2}{|c|}{ London DTM\&H } & \multirow[b]{2}{*}{ Remarks } \\
\hline & & Pass & Fail & \\
\hline 1998 (April) & 7 & 2 & 2 & $\begin{array}{l}\text { Three doctors did not sit the } \\
\text { examination in London }\end{array}$ \\
\hline 1999 & 6 & 5 & 0 & One doctor withdrew because of illness \\
\hline 2000 & 6 & 3 & 3 & $\begin{array}{l}\text { Two failed doctors had borderline fail } \\
\text { in MCQs }\end{array}$ \\
\hline 2001 & 4 & 2 & - & Two doctors failed mock examination \\
\hline 2002 & 6 & 5 & - & One doctor failed mock examination \\
\hline 2003 & 6 & 4 & - & Two doctors failed mock examination \\
\hline Total & 35 & 21 & 5 & \\
\hline
\end{tabular}

DTM\&H examination is in five parts: multiple choice questions (MCQs), preventative medicine paper, projected materials examination, practical examination, clinical viva voce. 
doctors apply for each course, but we select only six after interview.

\section{FUTURE PROSPECTS FOR THE OMAN DTM\&H COURSE}

It has been suggested that a full time course of 12-14 weeks could be introduced in Oman, along the lines of similar courses in the UK, initially with the enrolment of 10-15 doctors, and with external examiners. The course would undoubtedly attract candidates from other Gulf and regional countries, especially unmarried Muslim women who find it culturally difficult to study overseas. The College of Medicine already conducts an annual Diploma in Child Health course with examiners from Glasgow, and the Part II MRCP examination is now completed in Muscat with external examiners from the UK. At present we lack the resources, especially laboratory facilities, to conduct a full time course, but it might be feasible in the foreseeable future.

The future survival of the Oman DTM\&H course will depend on Omani doctors with tropical health experience to take over from existing expatriate staff. There are many Omani doctors currently receiving overseas training in various specialties, and it is hoped that some will develop an interest in tropical medicine, and spend a minimum of 12 months in a recognised tropical location. Oman, with its excellent health system, a progressive, research orientated university, and a stable administration, is well placed to become a focal point for tropical medicine teaching and research for the entire region.

\section{ACKNOWLEDGEMENTS}

Many people have contributed to the success of the Oman DTM\&H course, notably Dr Ali T Al-Hinai, Executive Director of the Oman Medical Specialty Board who supported its inception, the Dean of Medicine, Dr Bazdawi M Al Riyami, for continuing encouragement, and in Oxford, Professor David A Warrell of the Oxford Centre for Tropical Medicine. The LSHTM has provided invaluable advice for our teaching programme. Our honorary tutors have generously given their time and expertise, and Dr John Ochei, Senior Laboratory Technician, has made a major contribution to the laboratory sessions. Professor Nicholas N Y Woodhouse kindly reviewed this article.

\section{REFERENCES}

1 Oldfield III EC, Wallace MR, Hyams KC, et al. Endemic infectious diseases of the Middle East. Rev Infect Dis 1991;13(suppl 3):S199-S217.

2 Quinn NE. The impact of diseases on military operations in the Persian Gulf. Milit Med 1982;147:728-34.

3 Baker MS, Strunk HK. Medical aspects of Persian Gulf operations: serious infections and communicable diseases of the Persian Gulf and Saudi Arabian Peninsula. Milit Med 1991;156:385-400.

4 Cook GC. From the Greenwich hulks to Old St Pancras: a history of tropical diseases in London. London: Athlone, 1992:338.

5 Scrimgeour EM. Communicable diseases in Saudi Arabia: an epidemiological review. Trop Dis Bull 1995;92:R75-R95.

6 Scrimgeour EM, Mehta FR, Suleiman MAJ. Infectious and tropical diseases in Oman: a review. Am J Trop Med Hyg 1999;61:920-5.

7 Scrimgeour EM. Scope of infectious and tropical diseases in the Middle East (editorial). Acta Trop 2001;80:117-8. 